thực hiện nghiên cứu này.

\section{TÀI LIỆ THAM KHẢO}

1. A multicenter comparison of lovastatin and cholestyramine therapy for severe primary hypercholesterolemia. The Lovastatin Study Group III. (1988). The Journal of the American Medical Association, 360(3):359-366.

2. Bradford R.H., Shear C.L., Chremos A.N., et al. (1991). Expanded Clinical Evaluation of Lovastatin (EXCEL) study results. I. Efficacy in modifying plasma lipoproteins and adverse event profile in 8245 patients with moderate hypercholesterolemia. Archives of Internal Medicine, 151:43-49.

3. Daniel I Swerdlow, David Preiss, Karoline B Kuchenbaecke, et al. (2015). HMG-coenzyme A reductase inhibition, type 2 diabetes, and bodyweight: evidence from genetic analysis and randomised trials. Lancet, 385(9965): $351-361$.

4. Hernáez A., Soria-Florido M.T., Schröder H. et al. (2019). Role of HDL function and LDL atherogenicity on cardiovascular risk: A comprehensive examination. PLoS One, 14(6):e0218533.

5. Krukemyer J.J., Talbert R.L. (1987). Lovastatin: A new cholesterol-lowering agent. Pharmacotherapy 7:198-210.

6. World Health Organisation. Obesity and overweight. 1 April 2020; <https:// www.who.int/en/news-room/fact-sheets/detail/ obesity-and-overweight> Accessed on August 5, 2020.

7. Wilczewska A.Z., Niemirowicz K., Markiewicz K.H., et al. (2012). Nanoparticles as drug delivery systems. Pharmacological reports: PR, 64(5):10201037.

\title{
NGHIÊN CỨU PHÂN LÂP VÀ XÁC ĐINHH HỢP CHẤT CẦN SA TỔNG HỢP 5-FLUORO-MDMB-PICA TRONG CÁC MẪU TANG VÂT THU TẠI VIỆT NAM TỪ 2018 - 2020
}

\section{TÓM TẮT}

Muc tiêu: Phân lập và tinh khiết hóa hợp chất 5FLUOROO-MDMB-PICA dùng làm chất chuẩn định tính và định lượng. Đối tượng và phương pháp: Mẫu cần sa tổng hợp chứa trong các dạng có Mỹ được thu thâpp trong các vu án tại Việt Nam từ năm 2018 đến 2020, được chiết nóng nhanh với dicloromethan ở nhiệt độ $40^{\circ} \mathrm{C}$ để thu được cao dicloromethan. Cao dicloromethan toàn phần được tiến hành phân lập bằng sắc ký cột để thu được hợp chất 5-FLUOROMDMB-PICA. Kết quả: Từ $10 \mathrm{~g}$ cao dicloromethan toàn phần, sau phân lập thu được $0,9 \mathrm{~g}$ hợp chất 5FLUORO-MDMB-PICA với đô tinh khiết 99,46\% trên HPLC-PDA. Cấu trúc của hợp chất 5-FLUORO-MDMBPICA đã được xác đinh dựa trên các phương pháp phân tích TLC, IR, UV, GC-MS, LC-MS, NMR. Kêt luận: Nghiên cứu đã phân lập và tinh khiết hóa thành công hợp chất 5-FLUORO-MDMB-PICA định hướng thiết lập làm chất đối chiếu phục vụ cho công tác kiểm nghiệm, giám định các mẫu cần sa tổng hợp, đáp ứng yêu cầu công tác điều tra tôi pham ma túy tai Viêt Nam.

Từ khóa: Cần sa tổng hợp, 5-FLUORO-MDMBPICA, sắc ký cột, HPLC-PDA.

\section{SUMMARY \\ ISOLATION AND IDENTIFICATION OF THE SYNTHETIC CANNABINOID 5-FLUORO-}

\footnotetext{
*Đại học Y Dượ TP Hồ Chí Minh

**Phân viên Khoa hoc hình sư TP HCM

Chịu trách nhiệm chính: Nguyễn Hùng Cường

Email: hungcuongkndc@gmail.com

Ngày nhận bài: 15/5/2021

Ngày phản biên khoa hoc: 8/6/2021

Ngày duyệt bài: 15/7/2021
}

Nguyễn Hùng Cường*, Nguyễn Đăng Tiến**

\section{MDMB-PICA IN CRIMINAL EVIDENCES IN} VIETNAM IN THE PERIOD OF 2018 - 2020

Objectives: Isolation, purification, and structural elucidation of 5 - FLUORO - MDMB - PICA compound to be used as a reference standard. Methods: Synthetic cannabis samples contained in American grass collected in criminal cases in Vietnam from 2018 to 2020, were rapidly hot-extracted with dichloromethane at $40 \mathrm{oC}$ to obtain total dichloromethane extract. Then, the total dichloromethane extract was separated by column chromatography to collect 5 - FLUORO - MDMB - PICA. Results: $0,9 \mathrm{~g}$ of 5 - FLUORO - MDMB - PICA was collected from $10 \mathrm{~g}$ of total dichloromethane extract with the purity of $99,46 \%$. The structure of 5 FLUORO - MDMB - PICA compound was elucidated by analytical methods TLC, IR, UV, GC-MS, LC-MS, NMR. Conclusions: In the study, 5-FLUORO-MDMB-PICA compound has been successfully isolated, purified, and structural elucidated. The compound could be potentially used as a reference standard for testing and assessing synthetic cannabis samples, meeting the requirements of investigating drug crimes in Vietnam.

Key words; Synthetic cannabinoids, 5 - FLUORO MDMB - PICA, column chromatography, HPLC-PDA

\section{I. ĐĂTT VẤN ĐỀ}

Ma túy truyền thống như thuốc phiện, heroin được sử dụng phổ biến với những dấu hiệu nghiện điển hình như mệt mỏi, suy giảm về thể trạng, trí óc. Tuy nhiên, hiện nay ở Việt Nam, xuất hiện nhiều loại ma túy mới thuộc nhóm cần sa tổng hợp (Synthetic Cannabinoids) với tác dụng nhanh và mạnh hơn nên được giới trẻ ưa 
thích. Phân Viên khoa hoc hình sự tai TP. HCM cho biết 5 - Fluoro - MDMB - PICA là một chất thuộc tiểu nhóm Indon carboxamid trong nhóm cần sa tổng hợp aminoalkylindol, được phát hiện chiếm phần lớn trong các vụ án ma túy tại các tỉnh, thành phố phía Nam từ năm 2018 đến 2020. Trước tình hình đó, Chính Phủ đã kịp thời ban hành Nghị định số 60/2020/ND-CP ngày 29 tháng 5 năm 2020 về sửa đổi, bổ sung danh mục các chất ma túy và tiền chất ${ }^{[1]}$, chính thức đưa chất 5 - Fluoro - MDMB - PICA vào danh mục các chất ma túy được quản lý của Pháp luật Việt Nam. Một trong những khó khăn hiện nay là tại Việt Nam chưa có chất chuẩn này để phục vụ công tác giám định, giá thành chất chuẩn nhập từ nước ngoài rất cao, thủ tục rất phức tạp vì là chất cấm, nên gây không ít khó khăn cho công tác giám định ma túy ở các địa phương của Việt Nam. Vì vậy, nghiên cứu được tiến hành nhằm góp phần thiết lập chất chuẩn kiểm nghiệm, định hướng xây dựng quy trình giám định các chất ma túy mới cho các cơ quan chức năng, xây dựng tiêu chuẩn quốc gia về An Ninh trong đâu tranh phòng chống tội phạm về ma túy, nhất là giúp định danh nhanh và chính xác trong các vụ án. Nghiên cứu được thực hiện tại Phân Viện khoa học hình sự TP. HCM nhằm phân lập, tinh khiết hóa 5 - Fluoro - MDMB - PICA từ mẩu cỏ Mỹ thu được của các vụ án. Định hướng sử dụng chất phân lập này như chất chuẩn định tính, định lượng trong các phòng thí nghiệm giám định ma túy trên toàn quốc.

\section{II. ĐỐI TƯợNG VÀ PHƯƠNG PHÁP NGHIÊN CỨU \\ 2.1. Nguyên liệu}

Nguồn gốc: Mẫu cỏ Mỹ thu thập từ các vụ án tai Viêt Nam từ năm 2018 đến 2020.

Mô tả: Mẫu cỏ Mỹ được đóng gói dưới dạng các gói thực vật khô, cắt nhỏ, tẩm mùi thơm đặc trưng, nhưng thực chất cỏ Mỹ là hỗn hợp cây cỏ thảo mộc xay nhỏ được tẩm ướp chất ma túy cần sa tổng hợp.

2.2. Hóa chất, dung môi, thuốc thử. Bản mỏng tráng sẵn pha thường silica gel F254 (Merck), chất hấp phụ silica gel pha thường (cõ hạt 40-63 $\mu \mathrm{m}$, Merck). Dung môi n-hexan, ethyl acetat, cloroform, methanol, dicloromethan, nước cất, toluen, aceton đạt tiêu chuẩn phân tích. Thuốc thử dung dịch sắt (III) clorid $10 \%$.

2.3. Thiết bị, dụng cụ. Máy quang phổ UV Vis Shimadzu PharmaSpec UV-1700, Máy đo phổ hồng ngoại (IR) Thermo scientific NICOLET iS50 FTIR, Máy đo phổ cộng hưởng từ hạt nhân (1HNMR, 13C-NMR, DEPT, HSQC, HMBC) Bruker
AvanceNEO 400Mhz, Máy sắc ký lỏng hiệu năng cao (HPLC) Shimadzu LC - 20AD/PDA tại Viện Kiểm nghiệm thuốc TP.HCM. Máy đo phổ khối Shimadzu LC-MS IT-TOF tại Phân Viên khoa hoc hình sự TP.HCM. Máy đo phổ khối Agilent Máy GC/MS Agilent 7890B tại Phân viện khoa học hình sự TP. HCM. Cột sắc ký và các dụng cụ thủy tinh phòng thí nghiệm.

\subsection{Phương pháp nghiên cứu}

Chiết xuất và phân lập. Lựa chọn dung môi chiết: Methanol, ethyl acetat, chloroform, dicloromethan là các dung môi hòa tan tốt 5 Fluoro - MDMB - PICA giúp chiết tối đa 5 - Fluoro - MDMB - PICA từ mẫu cỏ Mỹ.

Mẫu cỏ Mỹ được sây khô, nghiền nhỏ thành bột mịn $(1,3 \mathrm{~kg})$, được chiết nóng nhanh với dicloromethan (3 lần, mỗi lần khoảng 2 lít). Lọc dịch chiết, cô quay dưới áp suất giảm thu được $113 \mathrm{~g}$ cao dicloromethan. $10 \mathrm{~g}$ cao toàn phần được hòa với lượng tối thiểu dicloromethan, tiến hành sắc ký cột pha thường, nạp cột ướt, rửa giải bằng dung môi $n$-hexan $100 \%$; hệ dung môi n-hexan - ethyl acetat với tỷ lệ 99,5:0,5; 99:1; 97:3; 95:5; 92,5:7,5; 90:10; 87,5:12,5; 85:15; $82,5: 17,5$. Kiểm tra bằng sắc ký lớp mỏng, thu được 4 phân đoạn khác nhau, ký hiệu F1, F2, F3, F4. Tinh chế các phân đoạn thu được $0,9 \mathrm{~g}$ tinh thể được ký hiệu là NC.

Xác định độ tinh khiết và câu trúc. Kiểm tra độ tinh khiết của hợp chất $\mathrm{NC}$ bằng sắc ký lớp mỏng và HPLC-PDA. Xác định cấu trúc của hợp chất $\mathrm{NC}$ bằng các phương pháp phổ nghiệm như TLC, IR, UV, GC-MS, LC-MS, NMR.

\section{KẾT QUẢ NGHIÊN CỨU}

3.1. Kết quả chiết xuất và phân lập. Cân khoảng $0,01 \mathrm{~g}$ cần sa tổng hợp rồi hòa với $5 \mathrm{ml}$ dung môi khảo sát, vortex 5 phút, sau đó siêu âm 10 phút, lọc qua màng lọc $0,45 \mu \mathrm{m}$. Thực hiện cùng điều kiện với 4 loại dung mổi: methanol, ethyl acetat, chloroform, dicloromethan. Kết quả diện tích đỉnh của pic chính trên GC/MS tại thời gian lưu 10,5 phút được trình bày như bảng 1 . Từ đó, lựa chon dung môi dicloromethan cho quá trình chiết mẫu do cho kết quả diện tích đỉnh lớn nhất.

Bảng 1. Kết quả xử lý với bốn loại dung môi

\begin{tabular}{|c|c|c|}
\hline Dung môi & $\begin{array}{c}\text { Khối lượng } \\
\text { cân (g) }\end{array}$ & $\begin{array}{c}\text { Diện tích } \\
\operatorname{pic}(\mu \mathrm{V} . \mathrm{min})\end{array}$ \\
\hline Methanol & 0,0100 & 612925142 \\
\hline Ethyl acetat & 0,0100 & 885767639 \\
\hline Chloroform & 0,0100 & 550790307 \\
\hline Dicloromethan & 0,0100 & 923644752 \\
\hline
\end{tabular}

Sau khi chiết với dicloromethan và tiến hành 
sắc ký cao dicloromethan trên cột sắc ký thu được 4 phân đoạn gồm: F1, F2, F3, F4, kiểm tra độ tinh khiết trền sắc ký lớp mỏng cho kết quả như hình 1.
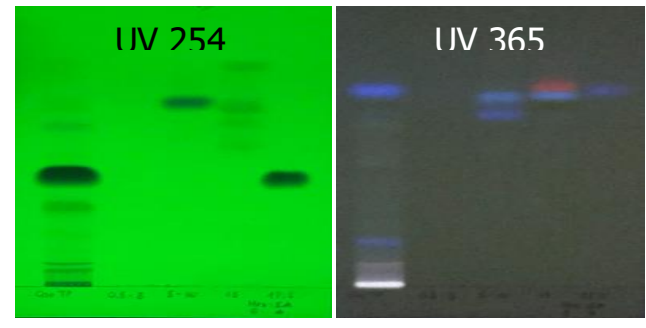

Hình 1. Sắc ký đồ ở các phân đoạn Hệ dung môi khai triển n-hexan ethylacetat $(6: 4)$
Lựa chọn phân đoạn F4 là phân đoạn sạch nhất trên sắc ký lớp mỏng, tiến hành cô quay, thu được tinh thể đăt tên là hợp chất NC. Hợp chất NC được tinh chế bằng cách kết tinh lại lần lượt với dung môi methanol, dichloromethan ở nhiệt độ phòng, thu được khoảng $0,9 \mathrm{~g}$ hợp chất NC tinh thể.

\subsection{Kiểm tra độ tinh khiết}

Sắc ký lớp mỏng: Hợp chất NC được khai triển với 3 hệ dung môi khác nhau, được phát hiện vết bằng dung dịch sắt (III) clorid $10 \%$. Hợp chất NC cho một vết duy nhất trên UV 254 nm và không thấy xuất hiện các tạp chất tại UV $365 \mathrm{~nm}$ và UV $254 \mathrm{~nm}$. Kết quả hợp chất NC tinh khiết trên sắc ký lớp mỏng được trình bày như hình 2.

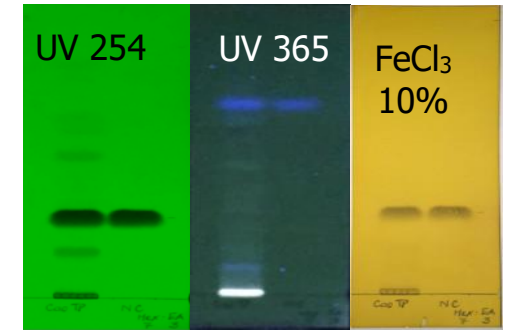

n-hexan-ethyl acetat

(7:3)

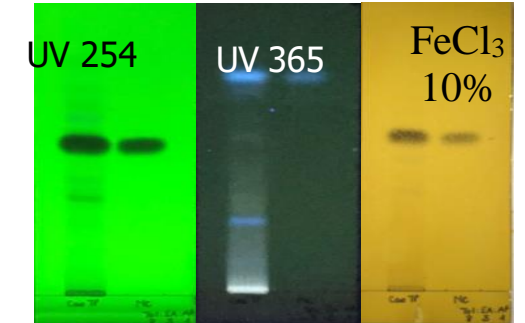

toluen - ethyl acetat - acid formic $(8: 3: 1)$

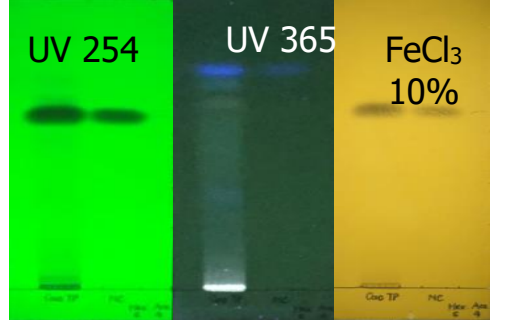

n-hexan - aceton $(6: 4)$

\section{Hinh 2. Hợp chất NC khai triển trên sắc ký lớp mỏng ở ba hệ dung môi}

Sắc ký lỏng hiệu năng cao với đầu dò PDA: Kết quả kiểm tra độ tinh khiết trên HPLC-PDA cho thấy hợp chất NC đạt được độ tinh khiết tính theo phần trăm diện tích pic ở bước sóng $210 \mathrm{~nm}, 254 \mathrm{~nm}$ và $290 \mathrm{~nm}$ lần lượt là 99,46\%; $99,76 \%$ và $99,79 \%$. Kết quả độ tinh khiết trên HPLC-PDA của hợp chất NC là trên $99 \%$.

3.3. Kết quả xác định cấu trúc

Phổ tử ngoại khả kiến: Phổ UV-Vis của hợp chất NC cho đỉnh hấp thu cực đại ở bước sóng $217,5 \mathrm{~nm}$ và $290,5 \mathrm{~nm}$.

Phổ hồng ngoại: Hợp chất NC cho các đỉnh ở số sóng 3437 (w), 2959 (m), 1729 (s), 1638 (s), $1496(\mathrm{~s}), 1234(\mathrm{~s}), 773(\mathrm{~m}), 751(\mathrm{~s}) \mathrm{cm}^{-1}$.

Phổ khối: Tiến hành quét phổ khối ESI $(+)$ IT-TOF của hợp chất NC. Kết quả cho đỉnh $\mathrm{m} / \mathrm{z}$ 377,2270 tương ứng với mảnh $[\mathrm{M}-\mathrm{H}]+$ của $5 \mathrm{~F}-$ MDMB-PICA.

Phổ cộng hưởng từ hat nhân: Phổ ${ }^{13} \mathrm{C}-\mathrm{NMR}$, ${ }^{1} \mathrm{H}-N M R$ cho kết quả phù hợp với cấu trúc của hợp chất 5F-MDMB-PICA trong nghiên cứu của Risseeuw ${ }^{[3]}$. Kết quả này cũng phù hợp với biện giải theo phổ DEPT và phổ HSQC trình bày như bảng 2.

Bảng 2. So sánh dữ liêu phổ NMR của hơp chât NC và 5-Fluoro-MDMB-PICA

\begin{tabular}{|c|c|c|c|c|c|c|c|c|c|}
\hline \multirow{2}{*}{$\begin{array}{c}\text { Vị } \\
\text { trí }\end{array}$} & \multicolumn{4}{|c|}{ Hợp chất NC (DMSO-d6) } & \multicolumn{3}{c|}{$\mathbf{H}$} & \multicolumn{3}{c|}{ 5F-MDMB-PICA (DMSO-d6) } \\
\hline
\end{tabular}


VIETNAM MEDICAL JOURNAL N01 - AUGUST - 2021

\begin{tabular}{|c|c|c|c|c|c|c|c|c|c|}
\hline $\mathbf{k}$ & $>\mathrm{CH}-$ & 109,8 & 7,53 & $\mathrm{~d}(8,1)$ & $1 \mathrm{H}$ & 110,3 & 7,54 & $\mathrm{~d}(8,0)$ & $1 \mathrm{H}$ \\
\hline I & $>\mathrm{CH}^{-}$ & 121,4 & 7,18 & $\mathrm{~m}$ & $1 \mathrm{H}$ & 122,0 & 7,19 & $\mathrm{dd}(8,0 ; 1,0)$ & $1 \mathrm{H}$ \\
\hline $\mathbf{m}$ & $>\mathrm{CH}-$ & 120,1 & 7,12 & $\mathrm{~m}$ & $1 \mathrm{H}$ & 120,7 & 7,15 & $\mathrm{dd}(8,0 ; 1,0)$ & $1 \mathrm{H}$ \\
\hline $\mathbf{n}$ & $>\mathrm{CH}-$ & 120,7 & 8,12 & $d(7,9)$ & $1 \mathrm{H}$ & 121,2 & 8,12 & $\mathrm{dd}(8,0 ; 1,0)$ & $1 \mathrm{H}$ \\
\hline 0 & $\mathrm{C}_{\mathrm{IV}}$ & 126,2 & & & & 126,7 & & & \\
\hline $\mathbf{p}$ & $-\mathrm{CH}_{2-}^{-}$ & 45,3 & 4,19 & $\mathrm{t}(7,2)$ & $2 \mathrm{H}$ & 45,8 & 4,22 & $t(7,2)$ & $2 \mathrm{H}$ \\
\hline q & $-\mathrm{CH}_{2-}^{-}$ & 28,8 & $1,89-1,81$ & $\mathrm{~m}$ & $2 \mathrm{H}$ & 29,3 & $1,90-1,80$ & $M$ & $2 \mathrm{H}$ \\
\hline $\mathbf{t}$ & $-\mathrm{CH}_{2}-$ & 83,9 & $\begin{array}{l}4,35 \\
4,46\end{array}$ & $\begin{array}{l}\mathrm{t}(6,0) \\
\mathrm{t}(6,0)\end{array}$ & $\frac{1 \mathrm{H}}{1 \mathrm{H}}$ & 83,6 & 4,42 & $\mathrm{dt}(47,4 ; 6,0)$ & $2 \mathrm{H}$ \\
\hline $\mathbf{S}$ & $-\mathrm{CH}_{2-}$ & 28,9 & $1,74-1,64$ & $\mathrm{~m}$ & $2 \mathrm{H}$ & 29,4 & $1,77-1,59$ & brm & $2 \mathrm{H}$ \\
\hline $\mathbf{r}$ & $-\mathrm{CH}_{2-}^{-}$ & 29,6 & $1,41-1,33$ & $\mathrm{~m}$ & $2 \mathrm{H}$ & 22,2 & $1,42-1,32$ & $M$ & $2 \mathrm{H}$ \\
\hline
\end{tabular}

Các dữ liệu phổ đều cho thây cấu trúc hợp chất NC phân lập được hoàn toàn phù hợp với cấu trúc của 5F-MDMB-PICA, công thức phân tử $\mathrm{C}_{21} \mathrm{H}_{29} \mathrm{FN}_{2} \mathrm{O}_{3}$ và có công thức cấu tạo như hình 3 .

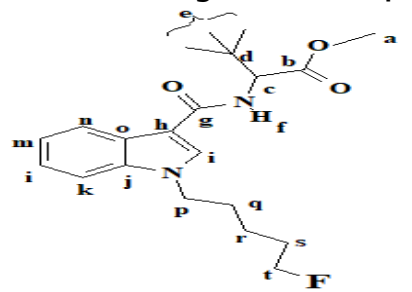

Hinh 3. Cấu trúc của hợp chất 5F-MDMB-PICA

\section{BÀN LUÂNN}

Nhóm nghiên cứu đã tiến hành khảo sát dung môi chiết mẫu cỏ Mỹ và đã lựa chọn dung môi chiết tối ưu dựa vào việc so sánh diên tích đỉnh của pic chính trên sắc ký đồ GC-MS. Kết quả bảng 1 cho thấy dung môi dicloromethan cho pic có diện tích đỉnh lớn nhất, kết quả này cũng hoàn toàn phù hợp với cấu trúc và độ tan của 5F-MDMB-PICA trong các dung môi, 5F-MDMBPICA tan tốt nhất trong dicloromethan. Nghiên cứu đã tiến hành khảo sát pha động có độ phân cực tăng dần trên sắc ký cột để tách 5F-MDMBPICA, sử dụng hệ pha động n-hexan - ethyl acetat với tỉ lệ ethyl acetat tăng dần từ $0 \%$ $17,5 \%$, kết quả cho thây trong 4 phân đoạn thu được từ cột sắc ký, phân đoạn F4 là phân đoạn sach nhất khi khai triển trên sắc ký lớp mỏng (Hình 1). Ngoài ra, F4 cũng chứa hợp chất có hàm lượng cao nhất trong cao toàn phần (được dự đoán là 5F-MDMB-PICA) khi khai triển với pha động n-hexan - ethyl acetat ( $6: 4)$. Vì thế, phân đoạn F4 này được lựa chọn để tiến hành phân lập và tinh chế. Hợp chất sau khi tinh chế được xác định độ tinh khiết bằng 3 hệ dung môi có độ phân cực khác nhau: n-hexan - ethyl acetat (7:3), toluen - ethyl acetat - acid formic (8:3:1), n-hexan - aceton (6:4), kết quả cho một vết duy nhất trên UV 254 nm, một vết duy nhất với thuốc thử sắt (III) clorid $10 \%$ và hoàn toàn không thấy xuất hiện các tạp chất tại UV 365nm và UV $254 \mathrm{~nm}$. Hợp chất 5F-MDMB-PICA được xác định cấu trúc bằng các phương pháp phổ học như: phổ tử ngoại khả kiến cho đỉnh hấp thu cực đại ở bước sóng $217,5 \mathrm{~nm}$ và $290,5 \mathrm{~nm}$ phù hợp với nghiên cứu của Tettey ${ }^{[6]}$, phổ hồng ngoại cho các đỉnh ở số sóng 3437 (w), 2959 (m), 1729 (s), $1638(\mathrm{~s}), 1496(\mathrm{~s}), 1234(\mathrm{~s}), 773(\mathrm{~m})$, $751(\mathrm{~s}) \mathrm{cm}^{-1}$ phù hợp với cấu trúc 5F-MDMB-PICA và tương thích với nghiên cứu của Banister [2], phổ khối ESI (+) IT-TOF cho kết quả đỉnh $\mathrm{m} / \mathrm{z}=$ 377,2270 tương ứng với mảnh $[\mathrm{M}-\mathrm{H}]+$ của hợp chất 5F-MDMB-PICA tương thích với nghiên cứu của Mogler ${ }^{[4]}$ và Kleis ${ }^{[5]}$, phổ NMR đã được biện giải và so sánh với nghiên cứu của Risseeuw [3]. Phân tích dữ liệu phổ NMR trong bảng 2 cho thây số lượng và vị trí của các carbon, proton phù hợp với công thức cấu tạo của 5F-MDMBPICA. Phổ ${ }^{13} \mathrm{C}-\mathrm{NMR}$ và phổ DEPT cho các tín hiệu có độ dời hóa học hoàn toàn phù hợp với 21 nguyền tử carbon trong cấu trúc 5F-MDMB-PICA. Kết quả phổ ${ }^{1} \mathrm{H}-\mathrm{NMR}$ và ${ }^{13} \mathrm{C}-\mathrm{NMR}$ cũng phù hợp với dữ liệu phân tích 5F-MDMB-PICA của nghiên cứu Risseeuww ${ }^{[3]}$. Từ các dữ liệu phổ $I R, M S$ và NMR, nhóm nghiên cứu xác định được câuu trúc của sản phẩm phân lập là 5F-MDMB-PICA $\left(\mathrm{C}_{21} \mathrm{H}_{29} \mathrm{FN}_{2} \mathrm{O}_{3}\right)$. Sản phẩm 5F-MDMB-PICA có độ tinh khiết đạt 99,46\% trên HPLC-PDA, đạt yêu cầu để thiết lập chất chuẩn phục vụ cho công tác xây dựng và thẩm định quy trình định lượng các mẩu cỏ Mỹ.

\section{KẾT LUÂ̂N}

Lựa chọn chiết bằng dicloromethan là tốt nhất, từ cao dicloromethan toàn phần, bằng kỹ thuật sắc ký, chúng tôi đã phân lập được hợp chất 5-FLUORO-MDMB-PICA đạt độ tinh khiết 99,46\%, định danh bằng các phương pháp TLC, IR, GC-MS, LC-MS, UV, NMR. Từ kết quả này, chất 5-FLUORO-MDMB-PICA có thể làm chất chuẩn trong kiểm nghiệm, góp phần xây dựng phương pháp phân tích các chất ma túy trong nhóm cần sa tổng hợp để hỗ trợ cho công tác giám định, điều tra tội phạm về ma túy của các 
cơ quan chức năng. Nghiên cứu cũng góp phần cập nhật tài liệu và thống nhất quy trình giám định các chất ma túy mới cần sa tổng hợp, tiến tới xây dựng tiêu chuẩn quốc gia về An Ninh trong giám định khoa học hình sự và đáp ứng yêu cầu đấu tranh phòng chống tội phạm ma túy.

\section{TÀI LIÊU THAM KHẢO}

1. Chính Phủ (2020), Nghị định số 60/2020/NĐ-CP ngày 29/05/2020 về sứa đổi, bổ sung danh mục các chất ma túy và tiền chất.

2. Banister, Samuel D., et al. "Pharmacology of valinate and tert-leucinate synthetic cannabinoids 5F-AMBICA，5F-AMB，5F-ADB， AMB-FUBINACA, MDMB-FUBINACA, MDMB-CHMICA, and their analogues.", ACS Chemical Neuroscience, 7.9 (2016), pp. '1241-1254.
3. Risseeuw, Martijn DP, et al. "Identification of a new tert-leucinate class synthetic cannabinoid in powder and "spice-like" herbal incenses: methyl 2[[1-(5-fluoropentyl) indole-3-carbonyl] amino]-3,3dimethyl-butanoate (5F-MDMB-PICA).", Forensic science international, 273 (2017), pp. 45-52.

4. Mogler, Lukas, et al. "Detection of the recently emerged synthetic cannabinoid 5F-MDMB-PICA in 'legal high'products and human urine samples." Drug testing and analysis 10.1 (2018): 196-205.

5. Kleis, J., et al. "The synthetic cannabinoid 5FMDMB-PICA: A case series." Forensic Science International 314 (2020): 110410.

6. Tettey, Justice NA, et al. "United Nations Office on Drugs and Crime: recommended methods for the identification and analysis of synthetic cannabinoid receptor agonists in seized materials." Forensic science international: Synergy 3 (2021).

\section{NHÂ̂N XÉT GIÁ TRI THYROGLOBULIN TRONG MÁU Ở BÊNH NHÂN UNG THƯ TUYẾN GIÁP THỂ BIẸTT HÓA ĐƯợC PHẪU THUẬT ĐIỀU TRI TẠI BỆNH VIỆN QUÂN Y 103}

\section{TÓM TẮT.}

Mục tiêu: Nồng độ Thyroglobulin huyết thanh được sử dụng để theo dõi sự tái phát hoặc tiến triển của ung thư tuyến giáp biệt hóa. Vai trò của việc định lượng thyroglobulin trước phẫu thuật còn chưa rõ ràng. Chúng tôi thực hiện nghiên cứu này nhằm góp phần đánh giá nồng độ thyroglobulin trước phẫu thuật và mối liên quan với một số yếu tố ở người bệnh ung thư tuyến giáp thể biệt hóa. Phương pháp: Nghiên cứu tiến cứu, mô tả cắt ngang; Dữ liệu được thu thập bao gồm nhân khẩu học, thyroglobulin trước phẩu thuật, kích thước $u$, tình trạng di căn hạch cổ và giai đoạn bệnh. Kết quả: Nồng độ thyroglobulin trung bình là 49,02 $\pm 78,71 \mathrm{ng} / \mathrm{ml}$. Có $33,3 \%$ bệnh nhân có thyroglobulin huyết thanh cao hơn giá trị bình thường. Mức tăng thyroglobulin huyết thanh trước phẫu thuật liên quan có ý nghĩa thống kê đến kích thước nhấn tuyến giáp, giai đoạn $T$ với $p<0,01$; không có liên quan đến tình trạng di căn hạch vùng cổ và bệnh viêm tuyến giáp kết hợp. Kết luận: Nồng độ thyroglobulin huyết thanh trước phẫu thuật có mối tương quan với kích thước và giai đoạn u nguyên phát.

Tư khóa: Ung thư tuyên giáp, thyroglobulin.

\section{SUMMARY \\ COMMENT ON SERUM LEVEL OF}

\footnotetext{
*Bệnh viện 103, Học viện Quân Y Chịu trách nhiệm chính: Vũ Anh Hải Email: vuanhhai.ncs@gmail.com Ngày nhận bài: 16/5/2021 Ngày phản biện khoa học: 25/6/2021 Ngày duyệt bài: 12/7/2021
}

Vũ Anh Hải*, Trần Xuân Bộ*

\section{THYROGLOBULIN IN PATIENTS WITH DIFFERENTIATED THYROID CANCER UNDERWENT THYROIDECTOMY AT MILITARY HOSPITAL 103}

Purpose: Serum level of thyroglobulin (TG) was used to monitor for recurrence or progression of differentiated thyroid cancer. The role of preoperative TG measurement is more ambiguous. We aimed this study to evaluate preoperative TG level and relative with other factors in differentiated thyroid cancer. Methods: A prospective, cross-sectional review; Data collected included demographics, preoperative TG, thyroid tumor size, cervical lymph node metastasis, and cancer stage. Results: The mean serum thyroglobulin concentration was 49,02 \pm $78,71 \mathrm{ng} / \mathrm{ml}$. There were $33,3 \%$ of patients who had increasing serum thyroglobulin concentration. Increasing in preoperative serum thyroglobulin was statistically significant to thyroid tumor size, stage $\mathrm{T}$ with $p<0.01$, had not been associated with cervical lymph node metastasis and combined thyroiditis. Conclusion: Preoperative TG level correlated significantly with the size of the primary tumor and T stage.

Key words: Thyroid cancer, thyroglobulin.

\section{I. ĐĂT VẤN ĐỀ}

Ung thư biểu mô tuyến giáp (UTBMTG) là bệnh ác tính thường gặp, chiếm $90 \%$ các trường hợp ung thư tuyến nội tiết và khoảng $1 \%$ các loại ung thư [1], [2]. Tân suất mắc bệnh hàng năm từ 0,5 - 10/100000 dân [3]. Tại Việt Nam, theo số liệu Globocan, số ca mắc mới trong năm 